\title{
A PSICOPEDAGOGIA E SUAS ESTRATÉGIAS FACILITADORAS NO PROCESSO DE APRENDIZAGEM
}

\author{
LA PSICOPEDAGOGÍA Y SUS ESTRATEGIAS DE FACILITACIÓN EN EL PROCESO \\ DE APRENDIZAJE
}

\author{
PSYCHOPEDAGOGY AND ITS FACILITATING STRATEGIES IN THE \\ LEARNING PROCESS
}

\author{
Anaisa Alves de MOURA ${ }^{1}$ \\ Evaneide Dourado MARTINS ${ }^{2}$ \\ Vithória Alves de MOURA ${ }^{3}$ \\ Adriana Pinto MARTINS ${ }^{4}$
}

RESUMO: A problemática básica que impulsionou este trabalho foi a de reafirmar que a Psicopedagogia contribui para a Educação ampliando as possibilidades de buscas e reflexões sobre o processo de aprendizagem. Analisar artigos de autores renomados como Grassi (2013), Bossa (2016) e Scoz (2013), afirmam que o trabalho do psicopedagogo institucional, favorece o professor ir ao encontro de condições de autoconhecimento, reconstruindo suas subjetividades, olhando para a sua história, sua existência e suas necessidades, sabendo mudar internamente para que se possam desencadear transformações satisfatórias na sua prática pedagógica. Assim, o presente artigo tem o objetivo de buscar uma melhor compreensão do processo de aprendizagem frente aos desafios a respeito dos distúrbios de aprendizagem e das possíveis estratégias a serem postas em prática. Utilizaram-se para a investigação diversos referenciais teóricos voltados para esclarecimentos sobre a importância do psicopedagogo, seu trabalho interventivo e preventivo e o seu papel junto ao ambiente escolar.

PALAVRAS-CHAVE: Psicopedagogia. Estratégias. Aprendizagem.

${ }^{1}$ Centro Universitário Inta (UNINTA), Sobral - CE - Brasil. Doutoranda em Educação - ULHT - Lisboa Portugal (2017). Mestre em Ciências da Educação - ULHT - Lisboa Portugal - Titulação reconhecida pela UFMG Universidade Federal de Minas Gerais - Brasil. Professora Pesquisadora pela CAPES desde 2013 e atualmente integra o grupo de pesquisas Narrativas autobibliográficas do CNPq. ORCID: <http://orcid.org/0000-0002-4878089X>. E-mail: anaisa1000@hotmail.com

${ }^{2}$ Centro Universitário Inta (UNINTA), Sobral - CE - Brasil. Atualmente é autora roteirista da Diretoria de Inovação Educacional do Centro Universitário - UNINTA. Atua como docente da UNIP no curso de Pedagogia. Especialista em Gestão, Coordenação, Planejamento e Avaliação Escolar, (2015), Especialista em Educação a Distância (2012) e Especialista em Docência do Ensino Superior (2019) pelo Instituto Superior de Teologia Aplicada-INTA.ORCID: <https://orcid.org/0000-0002-3075-9275>. E-mail: neidedouradomartins@ hotmail.com ${ }^{3}$ Faculdade Luciano Feijão (FLF), Sobral - CE. Discente em Psicologia. ORCID: <http://orcid.org/0000-00020200-6962>. E-mail: vithoria.alves@ hotmail.com

${ }^{4}$ Centro Universitário Inta (UNINTA), Sobral - CE - Brasil. Mestranda em Gestão Pública e Saúde Coletiva. É especialista em Gestão Escolar pelo Instituto EDUCAR (2014). Pedagoga pela Universidade Estadual Vale do Acaraú - UVA (2003). Desenvolveu trabalhos como Supervisora Pedagógica pela Secretaria de Educação do município de Ipu/Ce (2009). Atualmente está como Coordenadora da Comissão Própria de Avaliação- CPACentro Universitário Inta- UNINTA. ORCID: <http://orcid.org/0000-0002-1866-6105>. E-mail: adriana.martins@uninta.br 
RESUMEN: El problema básico que impulsó este trabajo fue reafirmar que la psicopedagogía contribuye a la educación ampliando las posibilidades de búsqueda y reflexiones sobre el proceso de aprendizaje. Analizar artículos de reconocidos autores como Grassi (2013), Bossa (2016) y Scoz (2013), que afirman que el trabajo del Psicopedagogo institucional, favorece al maestro para que cumpla con las condiciones de autoconocimiento, reconstruyendo sus subjetividades, buscando Por su historia, su existencia y sus necesidades, sabiendo cambiar internamente para que puedan desencadenar transformaciones satisfactorias en su práctica pedagógica. Por lo tanto, este artículo tiene como objetivo buscar una mejor comprensión del proceso de aprendizaje en relación con los desafios de los trastornos del aprendizaje y las posibles estrategias que se implementarán. Se utilizaron varias referencias teóricas para investigar la importancia de la psicopedagoga, su trabajo de intervención y prevención y su papel en el entorno escolar.

PALABRAS CLAVE: Psicopedagogía. Estrategias. Aprendizaje.

ABSTRACT: The basic problem that boosted this work was to reaffirm that psychopedagogy contributes to education by expanding the possibilities of searching and reflections on the learning process. Analyze articles by renowned authors such as Grassi (2013), Bossa (2016) and Scoz (2013), who affirm that the work of the institutional psychopedagogue, favors the teacher to meet conditions of self-knowledge, rebuilding his subjectivities, looking for their history, their existence and their needs, knowing to change internally so that they can trigger satisfactory transformations in their pedagogical practice. Thus, this article aims to seek a better understanding of the learning process in relation to the challenges of learning disorders and possible strategies to be implemented. Several theoretical references were used to investigate the importance of the Psychopedagogue, its interventive and preventive work and its role in the school environment.

KEYWORDS: Psychopedagogy. Strategies. Learning.

\section{Introdução}

O trabalho ora apresentado tem como temática “A Psicopedagogia e suas estratégias que facilitam o processo de aprendizagem", considerando o papel fundamental do psicopedagogo dentro do contexto escolar, como participante da equipe multidisciplinar que pretende o sucesso do aluno.

Neste âmbito, as questões que embasaram este trabalho foram assim determinadas: como as estratégias diferenciadas propostas pelos psicopedagogos podem auxiliar os professores e alunos na aprendizagem? Quais as ações desenvolvidas em consonância com o Plano Político Pedagógico da escola que podem ser desenvolvidas a partir da ótica da psicopedagogia? 
Nos últimos anos, com o acesso à escola garantido para a maioria das crianças brasileiras, cada vez mais existe a preocupação com a melhoria da qualidade da educação, principalmente na escola pública. Para responder a esse desafio, é urgente que a escola promova mudanças na sua estrutura, organização e, principalmente, nas práticas pedagógicas. Por isso, é de suma importância a formação de professores seja ela, inicial ou continuada, no sentido de buscar promover as condições para que a escola cumpra efetivamente sua função de ensinar e formar cidadãos, que sejam ativos na construção de uma sociedade caracterizada por equidade e justiça. Essa área da psicopedagogia trabalha com os processos de aprendizagem, em virtude disso acontece a preocupação de formação continuada desses profissionais (DROUET, 2015).

Ela também contribui para uma área de conhecimento interdisciplinar, valoriza a construção da educação mais ampla que pode interagir as diversas áreas de conhecimentos, na construção dos saberes do aluno, atuando assim, como caráter preventivo que evita ou minimiza situações de insucessos.

Este recurso oferece ao professor, juntamente com o psicopedagogo, um auxílio no trabalho, atuando diretamente nos problemas da aprendizagem, amenizando-o, descobrindo no aprendente suas capacidades e desenvolvendo atividades que o auxiliam na ordenação e coordenação de suas ideias e manifestações intelectuais.

O objetivo geral deste trabalho é de buscar uma melhor compreensão do processo de aprendizagem frente aos desafios a respeito dos distúrbios de aprendizagem e das possíveis estratégias a serem postas em prática.

A metodologia utilizada para pesquisa é exploratória, de cunho qualitativo, tendo como base a pesquisa bibliográfica a partir da análise acurada de estudiosos que se debruçaram sobre a temática e artigos científicos divulgados pelos meios eletrônicos, levando em consideração como critério a atualização das informações contidas nos periódicos. A pesquisa ocorreu entre os meses de agosto a novembro de 2018.

As teorias que serviram de base a este estudo vieram de autores como Drouet (2015), Scoz (2013), Soares (2014), Andrade (2015), Barbosa (2016) e Bossa (2016).

\section{Breve histórico da psicopedagogia}

O surgimento da Psicopedagogia ocorre na Europa no século XX. Porém, não se tem precisamente o ano, pois ainda não é um dado consensual na literatura. Segundo Andrade (2015, 
p. 76), “o surgimento ocorreu na década de 1920, na qual foi instituído o primeiro Centro de Psicopedagogia do mundo".

Já Bossa (2016) e Scoz (2014), por outro lado, apontam que a Psicopedagogia teria surgido no ano de 1946, período em que se deu a criação dos primeiros Centros Psicopedagógicos na Europa.

A Psicopedagogia iniciada nesses centros tinha, entre os seus objetivos centrais, auxiliar as crianças e os adolescentes que apresentavam dificuldades de comportamento (na escola ou na família), segundo os padrões da época, com o objetivo de reeducá-las para o seu ambiente por meio de um acompanhamento psicopedagógico (BOSSA, 1994).

Tal prática de reeducação consistia em identificar e tratar dificuldades de aprendizagem partindo de ações de medição, de classificação de desvios e de elaboração de planos de trabalho. Nos estudos de Andrade (2015, p. 58), ela afirma que "o conhecimento necessário para essa prática pertencia à Psicologia, a Psicanálise e Pedagogia e o tipo de enfoque predominantemente era o médico-pedagógico".

A Argentina foi uma das maiores influenciadoras da Psicopedagogia, período em que países da América Latina eram governados autoritários, por isso, a Psicopedagogia foi inserida para nós de modo clandestino (ANDRADE, 2015). Assim como na Argentina, a Psicopedagogia no Brasil também se construiu sob um enfoque médico-pedagógico e com uma natureza mais prática do que acadêmica. De um modo mais preventivo, o Brasil já tinha contado com uma iniciativa de trabalho psicopedagógico, especialmente voltada para a relação professor-aluno.

Entretanto, a literatura mostra que a finalidade que prevaleceu na história antiga da Psicopedagogia brasileira foi a de atuar nos problemas referentes às disfunções neurológicas ou, mais precisamente, naquilo que foi denominado na época de "Disfunção Cerebral Mínima" (DCM) (BOSSA, 2016).

Somente após quase vinte anos da efetiva prática psicopedagógica no Brasil, em 1979, surgiu o primeiro curso de especialização em Psicopedagogia do país, inicialmente chamado de Curso de Reeducação Psicopedagógica. Ele foi criado no Instituto Sedes Sapientiae (SP) e não era legalmente reconhecido.

Embora ainda hoje o país mantenha a tradição de formação psicopedagógica nos cursos de especialização, em meados dos anos 2000, a Psicopedagogia brasileira começou a almejar grandes progressos, criando outros tipos de cursos de formação na área, originando em um grande significativo aumento da produção acadêmica dentro desse campo (FONTES, 2006). 


\section{A prática e o perfil do psicopedagogo no âmbito escolar e sua valorização}

A prática psicopedagógica é entendida como o conhecimento dos processos de aprendizagem em seus mais diversos aspectos: cognitivos, emocionais ou corporais. $\mathrm{O}$ trabalho psicopedagógico está inserido no processo ensino-aprendizagem, atuando junto aos profissionais envolvidos nas instituições escolares como forma de prevenção, detectando os momentos de dificuldades e prevendo questões que seriam motivo de tratamento futuro na vida educacional dos aprendentes, como também, interagindo com o organograma escolar quando os problemas de dificuldades de aprendizagem já estiverem instalados, trabalhando nos diagnósticos e nas terapias psicopedagógicas.

O psicopedagogo é um profissional apto a trabalhar na área clínica e institucional, que pode ser no âmbito escolar, em hospital em ambiente empresarial. No Brasil, só poderão exercer a profissão de psicopedagogo os portadores de certificado de conclusão em curso de especialização em psicopedagogia em nível de pós-graduação, expedido por instituições devidamente autorizadas ou credenciadas nos termos da lei vigente-Resolução 12/83, de 06/10/83 - que forma os especialistas (CFE, 1983).

O psicopedagogo pode atuar em diversas áreas, de forma preventiva e terapêutica, para compreender os processos de desenvolvimento e das aprendizagens humanas, recorrendo a várias estratégias objetivando-se ocupar dos problemas que possam surgir.

O profissional habilitado na área da psicopedagogia em sua atuação percebe dificuldades no processo de aprendizagem do estudante, a partir desta constatação realiza a integração, promovendo orientações. No quesito assistencial, o profissional trabalha juntamente com professores, gestores e coordenadores auxiliando-os a repensar o papel da escola em relação à aprendizagem do educando (BOSSA, 2016).

Numa linha preventiva, o psicopedagogo pode desempenhar uma prática docente, envolvendo a preparação de profissionais da educação, ou atuar dentro da própria escola. Visto que sua função é de caráter preventivo, cabe ao psicopedagogo detectar possíveis inquietações no processo de aprendizagem e a partir da sua percepção tomará as devidas providências. Durante todo esse processo esse profissional deve ser um mediador, indo além da simples junção dos conhecimentos da psicologia e da pedagogia. O psicopedagogo pode atuar tanto na área da saúde como da educação, já que o seu saber visa compreender as variadas dimensões da aprendizagem humana. Numa linha terapêutica, "o psicopedagogo trata das dificuldades de aprendizagem, diagnosticando, desenvolvendo técnicas remediativas, orientando pais e 
professores, estabelecendo contato com outros profissionais da área de psicológica, psicomotora, fonoaudiologia e educacional" (GRASSI, 2013, p.64).

Da mesma forma, tem a possibilidade de trabalhar com crianças hospitalizadas e seu processo de aprendizagem em parceria com a equipe multidisciplinar da instituição hospitalar, tais como psicólogos, assistentes sociais, enfermeiros e médicos. No campo empresarial, o psicopedagogo pode contribuir com as relações inter e intrapessoais dos indivíduos que trabalham na empresa.

O diagnóstico realizado pelo psicopedagogo é um trabalho inicial de identificação, onde acontece a investigação e a intervenção, porém ambas ocorrem concomitantemente com a finalidade de acompanhar a evolução do indivíduo (BOSSA, 2016).

Diante do baixo desempenho acadêmico, as escolas estão cada vez mais preocupadas com os estudantes que têm dificuldades de aprendizagem, não sabem mais como agir com as crianças que não conseguem aprender de acordo com o processo considerado normal e não possuem uma política de intervenção capaz de contribuir para a superação dos problemas de aprendizagem.

É nesse contexto em que o psicopedagogo institucional, como um profissional qualificado, está apto a trabalhar no âmbito educacional, dando assistência aos professores e a outros profissionais da instituição escolar para a prevenção dos problemas e melhoria das condições do processo ensino-aprendizagem. Ele identifica problemas de aprendizagem que podem levar a repetência sequenciada e a evasão escolar, conduzindo a identidade, este profissional detém um corpo de conhecimentos científicos oriundos da articulação de várias áreas. Segundo Libâneo (2016, p. 90), “a escola reflete as características observadas na vida social mais ampla: as relações hierárquicas de poder, a fragmentação e a burocratização do trabalho pedagógico".

O psicopedagogo deve tomar cuidado em burocratizar o trabalho do docente, pois seu foco deve ser em desenvolver condições positivas nos processos educativos. Seu objetivo deve ser de reinserir o indivíduo, seja criança, adolescente ou adulto numa aprendizagem satisfatória e saudável (LIBÂNEO, 2016).

Observa-se que o psicopedagogo é o profissional de ação, cuja práxis implica um amplo conjunto de atitudes, que envolve a si mesmo e aos outros enquanto seres humanos nos processos de aprendizagem, o procedimento psicopedagógico está na atitude daquele que interpela o sujeito da aprendizagem, e sua abordagem é encontrada nos ensinamentos tácitos e na sua visão de mundo. 
Ao refletir um pouco sobre a aprendizagem, pode-se dizer que, desde o momento em que nascemos, iniciamos o processo de aprendizagem. Diante disso, o ser humano constrói sua estrutura de personalidade na trama de relações sociais na qual está inserido. Enquanto "transforma a realidade a sua volta, ele constrói a si mesmo, tecendo sua rede de saberes, a partir da qual irá interagir com o meio social, determinando suas ações, suas reações, enfim suas práticas sociais" (BARBOSA, 2016, p. 87).

A aprendizagem ocorre na estimulação do ambiente sobre o indivíduo maturo, onde, diante de uma situação/problema, se expressa uma mudança de comportamento, recebendo interferência de vários fatores: intelectual, psicomotor, físico, social e emocional.

Professores elaboram seus planos de ensino, mas será que se indagam se a didática utilizada está de acordo com a proposta pedagógica da escola, ou simplesmente ignoram e/ou não adotam nenhum critério (SCOZ, 2013).

Dentro das instituições nossa rede de conhecimentos vai se formando, por isso é necessário inserir a psicopedagogia para estudar como ocorrem as relações interpessoais nestes ambientes. Além da escola, a psicopedagogia está cada vez mais presente nos hospitais e empresas. Seu papel é analisar e apontar os fatores que favorecem, intervêm ou prejudicam uma boa aprendizagem em uma instituição.

O psicopedagogo atua de forma preventiva sendo indicado para assessorar e esclarecer a escola a respeito de diversos aspectos do processo de ensino-aprendizagem. No âmbito escolar, esse profissional contribui no esclarecimento de dificuldades de aprendizagem que não têm como causa apenas deficiências do aluno, mas que são consequências de problemas escolares, tais como: organização da instituição, métodos de ensino, relação professor/aluno, linguagem do professor, dentre outros. Ele poderá atuar preventivamente junto aos professores.

O psicopedagogo deve conhecer os elementos que fazem com que o sujeito aprenda isso contribuirá para o avanço daqueles que tem dificuldades de aprendizagem (BOSSA, 2016). No entanto, segundo Soares (2014), a psicopedagogia possibilita estudar as características da aprendizagem humana, como é o processo de aprendizagem e com a habilidade de reconhecer quais os fatores que influenciam na aprendizagem inserindo um tratamento adequado.

O psicopedagogo, por sua vez, tem a função de observar e avaliar qual a verdadeira necessidade da escola e atender aos seus anseios, bem como verificar, junto ao projeto políticopedagógico, como a escola conduz o processo ensino-aprendizagem, como garante o sucesso de seus alunos e como a família exerce o seu papel em parceria. Considerando a escola responsável por grande parte da formação do ser humano, disponibiliza um psicopedagogo através de um trabalho preventivo para solucionar problemas (ANDRADE, 2015). 
O papel do psicopedagogo escolar é de suma importância, pois pode e deve ser pensado a partir da instituição, a qual cumpre uma função social que é socializar os conhecimentos disponíveis, promover o desenvolvimento cognitivo, ou seja, através da aprendizagem, o sujeito é inserido, de forma mais organizada no mundo cultural e simbólico, que incorpora a sociedade.

Vygotsky (2012, p. 21) ao considerar a aprendizagem como profundamente social, afirma que "quando os pais ajudam e orientam a criança desde o início de sua vida, dão a ela uma atenção social mediada, e assim desenvolvem um tipo de atenção voluntária e mais independente, que ela utilizará na classificação e organização de seu ambiente".

Tal consideração se baseia no fundamento de que o homem se torna humano, apropriando- se da humanidade produzida historicamente. $\mathrm{O}$ ensino tem nesse contexto, a função de transmitir as experiências histórico-sociais que se modificam no decorrer dos tempos.

O psicopedagogo está sendo valorizado visto que, tem havido um crescimento de materiais científicos produzidos e publicados. Desta forma, a psicopedagogia preventiva com comprovações, em uma dimensão institucional, quando aceita e sem preconceitos é vista de forma diferente para a melhoria da aprendizagem (GRASSI, 2013).

A presença de psicopedagogos no espaço das instituições educacionais é um fator interessante de construir estratégias, onde será possível fazer uso das diferentes articulações teóricas e práticas do campo psicopedagógico, propondo à melhoria de qualidade das relações interpessoais na vivência dos objetivos contidos na missão de cada instituição. "O gestor educacional consciente dos propósitos de melhoria humana perceberá a essencialidade deste trabalho, pois sabe o quanto é importante conhecer outras possibilidades de interpretação e atuação diante da realidade" (LIBÂNEO, 2016, p. 58).

Segundo Bossa (2016), o psicopedagogo pode colaborar na elaboração do projeto pedagógico, ou seja, através de seus conhecimentos ajudar a escola a responder questões fundamentais como: O que ensinar? Como ensinar? Para que ensinar? Pode realizar o diagnóstico institucional para detectar problemas pedagógicos que esteja prejudicando a qualidade do processo ensino-aprendizagem; ajudar o professor a perceber quando a sua maneira de ensinar não é apropriada à forma do aluno aprender; orientar o professor no acompanhamento do aluno com dificuldades de aprendizagem; e ainda, realizar encaminhamentos para fonoaudiólogo, psicólogo, neurologista, psiquiatras entre outros. 


\section{Os desafios dos distúrbios de aprendizagem sob o enfoque psicopedagógico}

O conceito referente aos distúrbios de aprendizagem diz respeito a problemas amplos nas manifestações de dificuldades mais significativas de aquisição e compreensão das capacidades do aprender. Nos estudos de Soares $(2014$, p. 75)

No Brasil, foi Lefèvre em 1975 que introduziu o termo distúrbio como: "síndrome que se refere à criança de inteligência à média ou superior à média, com problemas de aprendizagem e/ou certos distúrbios do comportamento de grau leve ou severo, associados a discretos desvios do funcionamento do Sistema Nervoso Central (SNC), que podem ser caracterizados por várias combinações de déficit na percepção, conceituação, linguagem, memória, atenção e na função motora".

Sendo assim, crianças que apresentam distúrbios de aprendizagem consequentemente “apresentam dificuldades de aquisição de matéria teórica, embora apresentem inteligência considerada normal. Os principais distúrbios são: Dislexia, falha no processamento da habilidade da leitura e da escrita durante o desenvolvimento" (ANDRADE, 2015, p.45). Segundo Scoz (2014, p. 77), “a dislexia consiste em alterações resultantes de limitações sensoriais discretas ou de anomalias na organização dinâmica dos circuitos cerebrais responsáveis pela coordenação viso-áudio-motora".

Os indivíduos que apresentam a dislexia são portadores de diferenças de aprendizagem específicas, não se tratando, portanto, de uma doença e sim de um modo diferente de pensar, não atribuindo uma incapacidade. As crianças, quando iniciam a alfabetização, já dominam a linguagem oral, sendo capazes de iniciar o aprendizado da escrita. No pensar de Scoz (2013, p. 132) afirma "que existem regras mais específicas e próprias da escrita, havendo, então, maiores dificuldades no seu aprendizado".

O disléxico apresenta uma alteração específica de leitura e de escrita, contudo, requer estudos mais aprofundados, por se tratar de um tema complexo. O aprendizado da leitura e da escrita é um marco na vida das crianças, entretanto, muitas destas apresentam dificuldades neste processamento e requerem que os profissionais se aprimorem sobre este assunto, para que a intervenção seja realizada precocemente. Segundo Bossa (2016, p. 75), “etimologicamente, trata-se de um distúrbio de origem neurológica, congênito e hereditário, sendo comum apresentar-se em parentes próximos".

Quando a dislexia é diagnosticada e tratada de forma precoce, os impactos emocionais e comportamentais são evitados e a criança consegue suprir suas dificuldades e continuar no processo de alfabetização. Para Soares (2014), diagnosticar esse déficit deve ser utilizado métodos para determinar o nível da funcionalidade da leitura, seu potencial e verificar a 
capacidade, o grau da deficiência, a disfunção neuropsicológica, e as táticas de recuperação com a finalidade de melhorar o processo neuropsicológico.

De acordo com Scoz (2013, p. 88) "a disgrafia é a falta de habilidade motora para transpor através da escrita o que captou no plano visual ou mental, a criança apresenta lentidão no traçado e letras ilegíveis. É uma desordem resultante de um distúrbio de integração visualmotora".

Isso ocorre devido a uma incapacidade de recordar agrafia da letra. Quando esse fator ocorrer, significa que a criança não possui deficiência visual, nem motor, e tão pouco qualquer comprometimento intelectual ou neurológico. No entanto, não consegue transmitir informações visuais ao sistema motor.

Há diversos estudos que mencionam que a disgrafia, ou seja, qualquer outra dificuldade que esteja atrelada ao ensino-aprendizagem deve a fatores sociais, emocionais e/ou até mesmo psicomotor (GRASSI, 2013).

A criança pode apresentar um ou dois tipos de disgrafia: Disgrafia motora (discaligrafia), onde a criança consegue falar e ler, mas encontra dificuldades na coordenação motora fina para escrever as letras, palavras e números, ou seja, vê a figura gráfica, mas não consegue fazer os movimentos pra escrever. E a disgrafia perceptiva na qual não consegue fazer a relação entre o sistema simbólico e as grafias que representam os sons, as palavras e frases. Possui as características da dislexia sendo que esta está associada à leitura e a disgrafia à escrita.

O tratamento necessita de uma intervenção individualizada do profissional complementar a escola. Os pais e professores devem evitar repreender a criança e buscar estimulá-la nas suas dificuldades e destacar seus progressos. No momento da avaliação o educador deve evitar corrigir as atividades dos estudantes utilizando canetas vermelhas e conscientizar o educando do problema que ele apresenta e auxiliá-lo em suas dificuldades. (ANDRADE, 2015).

A falta de capacidade de compreender e a habilidade com os símbolos dos processos matemáticos denomina-se discalculia sendo considerado um distúrbio de aprendizagem na área da matemática. Conforme Barbosa (2016, p. 43) “A palavra discalculia vem do grego (dis, mal) e do latim (calculare, contar) formando: contando mal. Essa palavra por calculare vem, por sua vez, de cálculo, que significa o seixo ou um dos contadores em um ábaco".

Esse distúrbio não é causado por deficiência mental, nem por déficit visual ou auditivo, nem por má escolarização. O portador de discalculia comete erros diversos na solução de problemas verbais, nas habilidades de contagem, nas habilidades computacionais, na compreensão dos números. Qualquer distúrbio diagnosticado pelo psicopedagogo deve ser 
realizado uma intervenção o mais rápido possível, com uma equipe multidisciplinar envolvendo a família e a escola, principalmente no início da identificação para que ocorra um tratamento mais eficaz (BOSSA, 2016).

Essas características podem levar o portador a ter dificuldades emocionais de relacionamento, resultando em baixos níveis de autoestima, além do mau desempenho escolar, face às reais dificuldades no aprendizado. Em muitos casos o portador apresenta falta de motivação, maior comprometimento em memória de trabalho, dificuldades em atividades de velocidade de processamento, falta de autoconfiança, baixo desempenho em realizar leitura e compreender textos; apresenta sintomas internalizantes, como depressão, ansiedade e dificuldades e flutuação na aprendizagem.

Esses sintomas aparecem de forma clara, principalmente dentro da sala de aula. Aos portadores de Transtorno do Déficit de Atenção com Hiperatividade (TDAH), que estão sob tratamento medicamentoso, é exigido o acompanhamento, devendo a escola estar em cumplicidade, de forma integral, durante todo o processo. A princípio, é à escola, a partir das dificuldades observadas, a competência para o primeiro encaminhamento ao diagnóstico/avaliação psicopedagógica, que poderá diferenciar fatores do aluno que o conduzam a outros encaminhamentos, mais especializados.

O psicopedagogo que acompanha a criança com TDAH deve realizar trabalhos em cima de suas dificuldades utilizando jogos, instigando a leitura e a escrita, trabalhos manuais juntamente com a ludicidade não esquecendo a organização da rotina e execução nas tarefas. (SOARES, 2014).

O profissional formado na área da psicopedagogia deve além de realizar um trabalho de reflexão com os pais, professores, adequar a criança à sua própria realidade, ampliando as possibilidades de aprendizagem e conhecimento. Assim, distúrbios relacionados à aprendizagem têm sido usados para indicar uma perturbação ou falha na aquisição e utilização de informações ou na habilidade para solução de problemas.

\section{As intervenções e as estratégias da psicopedagogia para o sucesso escolar}

A função do psicopedagogo é de intervir como mediador. Assim, essa intervenção deve ser em um primeiro momento preventiva. Esse trabalho preventivo visa precaver possíveis problemas de aprendizagem e deve ter caráter investigativo. Porém, quando a criança já apresenta distúrbios, faz-se necessário a intervenção. Sendo assim, depois de adequado 
diagnóstico que aponte para os tipos de distúrbios e modo de funcionamento da criança, devese programar uma ação interventiva.

Essa programação deve ocorrer a partir do momento que o psicopedagogo percebe alguma anormalidade no processo de aprendizagem da criança ou adolescente propiciando uma integração e realizando orientações (GRASSI, 2015).

Faz-se necessário investigar sobre os problemas encontrados, os reais motivos dos distúrbios e dificuldades que, em alguns possíveis casos será de falta de atenção e/ou desinteresse. Entretanto, ao avaliar essas questões encontrarão alguns que necessitam de intervenção psicopedagógica e, em alguns casos, de intervenção psicológica. Por isso, se faz tão necessário a avaliação em buscar alternativas e diagnósticos.

Após o diagnóstico ocorrerá a intervenção, esta está atrelada ao processo de ensinoaprendizagem, assim como também a relação entre professores e estudantes. Tanto o distúrbio como a indisciplina são fatores em que o psicopedagogo intervirá e ajudará a solucionar os problemas (DROUET, 2015).

Outro fator importante que deve ser mencionado, para que seja realizada uma pertinente intervenção, é a necessidade de o profissional conhecer o processo de ensino-aprendizagem, como interferem nos sistemas e nos métodos educativos, nos problemas estruturais que intervêm. Esse conhecimento requer do psicopedagogo recorrer as teorias embasadas no processo de aprendizagem e as influências afetivas (BOSSA, 2016). Dentro da instituição escolar a aprendizagem é considerada entre todos os envolvidos um movimento de interação que resulta em descobertas e construção do conhecimento (BARBOSA, 2016).

A Psicopedagogia contribui muito nas instituições educacionais, no entanto o profissional qualificado tem um papel desafiador exigindo uma postura de ver o sujeito na totalidade (SCOZ, 2013). Por isso, que a ação do psicopedagogo é muito importante possibilitando uma intervenção e reorganização do processo de aprendizagem dos indivíduos, utilizam de oficinas como suporte à intervenção.

Os alunos que apresentam insegurança e medo dos fracassos no processo de aprendizagem e professores sendo julgados e sentindo-se responsáveis pela reprovação dos educandos, pela falta de interesse destes e até mesmo sentindo-se desmotivados no ato de ensinar tem sido um dos fatores importantes em que o psicopedagogo possa pensar em aplicar oficinas com a finalidade de amenizar ou solucionar o problema. Segundo Grassi (2013, p. 95), "a perspectiva criada a partir dessa proposta com Oficinas Psicopedagógicas deve estar voltada para redescoberta, para a criação e a recriação, para a construção permanente de outros caminhos para conviver em processo de ensinagem". 
Fazer uso das oficinas psicopedagógicas como suporte à intervenção institucional auxilia o profissional conhecer o sujeito, sua relação consigo mesmo, com os outros e com o conhecimento, o que pode ajudar na compreensão de suas dificuldades. Nas escolas, com a queixa apresentada, a realização da oficina psicopedagógica se faz com o corpo docente e equipe diretiva/pedagógica, conforme instrui Grassi (2013, p. 64) dizendo "que permite a análise de diversos fatores e a observação de uma série de aspectos necessários ao diagnóstico psicopedagógico".

Assim, a possibilidade da superação das dificuldades torna-se mais próxima, possibilita a melhora das relações interpessoais, promove a elaboração e a organização de sentimentos e pensamentos, aumenta a autoestima e facilita o autoconhecimento permitindo a tomada de consciência de suas possibilidades e limites.

A atuação do psicopedagogo na escola é ajudar o coordenador pedagógico elaborando estratégias e orientar o corpo docente em relação as dificuldades vivenciadas pelo professor e pelos estudantes (GRASSI, 2013).

Como exemplo prático, pode-se trabalhar com a proposta de Oficina Psicopedagógica que apresenta quatro passos a serem seguidos: sensibilização, desenvolvimento com jogos e dinâmicas, no fechamento reflexões e avaliação das vivências de forma crítica (GRASSI, 2013).

As oficinas são momentos de diagnóstico, de conhecimento, interação, superação e planejamento das ações que proporcionarão ao psicopedagogo elaborar suas estratégias que reduzam as dificuldades de aprendizagem e facilitem o processo de ensino-aprendizagem. São várias as estratégias a serem utilizadas, porém nenhuma mais eficaz que inserir efetivamente a família nas ações escolares e quando da detecção de distúrbios, que sejam tomadas medidas imediatas para a redução dos resultados prejudiciais destes distúrbios através das intervenções do psicopedagogo, em parceria com a comunidade escolar.

\section{Considerações finais}

Este trabalho propôs uma discussão de como a Psicopedagogia poderia contribuir para facilitar a aprendizagem através de estratégias e ações direcionadas para o atendimento das necessidades dos alunos e, consequentemente, da melhoria do processo educacional em si.

$\mathrm{Na}$ instituição escolar o psicopedagogo tem a percepção de detectar falha na área funcional, onde os envolvidos no processo não conseguem se comprometer com a escola devido a vários fatores como: a relação dos alunos, professores e gestores com a própria escola, onde 
ambos não se sentiam valorizados, estimulados, reconhecidos, caracterizando uma falta de interesse pela escola e um grande grau de exigência de participação de todos. Com isso, a figura do psicopedagogo é de fundamental importância, pois através da intervenção realizada possibilitará o resgate do estudante para dentro da escola e fazer com que a escola repense sobre sua atuação.

O trabalho pode ser iniciado com as tipologias de estratégias a serem utilizadas pelos psicopedagogos, utilizando-se a oficina psicopedagógica como parceira da psicopedagogia institucional no processo de ensinar e aprender, levando o professor a refletir sobre a valorização da sua profissão em parceria com o psicopedagogo.

Após a análise dos que os autores pesquisaram sobre a atuação do psicopedagogo no âmbito escolar como instrumento importante para a facilitação do processo de aprendizagem. Os docentes e educandos se sentem mais importantes no processo, tendo a oportunidade de criar, recriar, aprender e ensinar, pois, todos passam a produzir obtendo melhores resultados nos seus saberes e fazeres. As estratégias que a Psicopedagogia oferece através de seus profissionais são indubitavelmente um caminho a ser explorado para o sucesso no processo de aprendizagem.

\section{REFERÊNCIAS}

ANDRADE, M. S. Rumos e diretrizes dos cursos de Psicopedagogia: análise crítica do surgimento da Psicopedagogia na América Latina. Cadernos de Psicopedagogia, v.3, n.6, 70-71, jun. 2015.

BARBOSA, L. M. S. A Psicopedagogia no âmbito da instituição escolar. Curitiba: Expoente, 2016.

BOSSA, N. A. A Psicopedagogia no Brasil: contribuições a partir da prática. Porto Alegre: Artmed, 2016.

BOSSA, N. A.; OLIVEIRA, V. B. Avaliação psicopedagógica da criança de zero a seis anos. Vozes, 1994.

CONSELHO FEDERAL DE EDUCAÇÃO. Resolução n¹2, de 06 de out. 1983. Fixa condições de validade dos certificados de cursos de aperfeiçoamento e especialização de para o Magistério Superior, no sistema federal, 1983.

DROUET, R. C. R. Distúrbios de Aprendizagem. São Paulo. Ática, 2015.

FONTES, M. A. Psicopedagogia e sociedade: história, concepções e contribuições. São Paulo: Vetor, 2006. 
GRASSI, T. M. Oficinas psicopedagógicas. Curitiba. Ibpex, 2013.

LIBÂNEO, J. C. Didática. São Paulo. Cortez, 2016.

SCOZ, B. Psicopedagogia e realidade escolar: o problema escolar e de aprendizagem. $2^{\mathrm{a}}$ ed. Petrópolis. RJ. Vozes, 2013.

SOARES, D. C. Indicadores para uma construção psicopedagógica. Disponível em: http://www.psicopedagogia.com.br/artigos/artigo.asp?entrlD=243. Acesso: 16 ago. 2018.

VYGOTSKY, L.S. A formação social da mente. São Paulo. Martins Fontes. 2012.

\section{Como referenciar este artigo}

MOURA, Anaisa Alves de; MARTINS, Evaneide Dourado; MOURA, Vithória Alves de; MARTINS, Adriana Pinto. A psicopedagogia e suas estratégias no processo de aprendizagem. Revista on line de Política e Gestão Educacional, Araraquara, v. 23, n. 2, p. 479-493, maio/ago., 2019. E-ISSN:1519-9029. DOI: 10.22633/rpge.v23i2.12654

Submetido em: 10/03/2019

Revisões requeridas: 15/04/2019

Aprovado em: 06/05/2019

Publicado em: 09/06/2019 